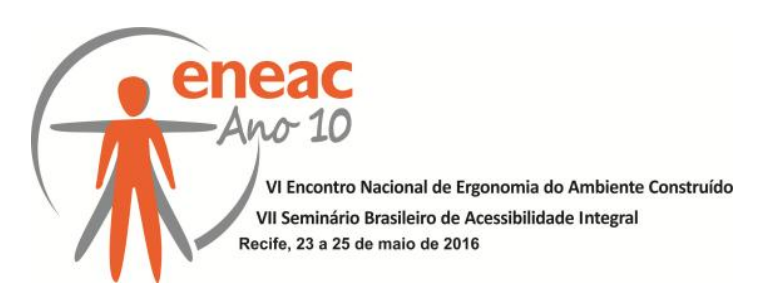

\title{
HABITAÇÃO ECONÔMICA, ACESSIBILIDADE E CONFORTO AMBIENTAL: UMA ABORDAGEM ERGONÔMICA DA MANEIRA COMO OS PROJETOS ESTÃO SENDO PENSADOS
}

\author{
CRESPILHO, Fabiana Estevam Eid (1); \\ BORMIO, Mariana Falcão Bormio (2); \\ STRABELI, Giovana Innocenti (3)
}

(1) UNESP, Mestranda

e-mail: fabiana_eid@hotmail.com

(2) Doutora

e-mail:marianabormio@uol.com.br

(3) USC, Mestre

e-mail: ginnocenti@hotmail.com

\begin{abstract}
RESUMO
Este trabalho apresenta os resultados de uma análise ergonômica desenvolvida em apartamentos construídos com verbas do programa de financiamento habitacional do governo federal chamado "Minha casa minha vida", no qual foram enfocados aspectos como acessibilidade, habitabilidade, desenho universal e conforto ambiental, buscando a geração de dados que auxiliem no entendimento das deficiências ou qualidades projetuais e consequentemente possam ser usadas como base técnica para novas propostas. Seu desenvolvimento ocorreu em etapas iniciando-se por revisão bibliográfica, desenvolvimento de metodologia especifica, cadastro de projeto: identificação, cadastro e visita técnica a conjuntos habitacionais financiados pelo sistema "Minha casa minha vida"; análise ergonômica projetual: análise dos projetos cadastrados e análise dos dados obtidos.
\end{abstract}

Palavras chave: análise ergonômica do ambiente construído; habitação social; metodologia ergonômica.

\begin{abstract}
This paper presents the results of an ergonomic analysis developed in apartments built with funds from the mortgage program of the federal government called "My home my live", which focused on aspects such as affordability, habitability, universal design and environmental comfort, searching to create knowledge to assist in understanding the deficiencies or projective qualities and consequently can be used as technical basis for new proposals. Its developing occurred in stages starting out by literature review, methodology developed specific, project register: identification, registration and technical visit to housing projects by the system "My home my live"; projectual ergonomic analysis: analysis of the registered projects and analysis of the data analysis.
\end{abstract}

Keywords: ergonomic analysis of the building environment; social housing; ergonomic methodology

\section{INTRODUÇÃO}

Nos últimos anos o setor de habitação brasileiro, em especial as de cunho popular, foi fortemente alavancado pelo programa de financiamento federal "Minha casa minha vida". Esse programa criado em 2009 tem como objetivo principal suprir um grande déficit habitacional existente no país, tornando a moradia acessível às famílias de diferentes faixas 


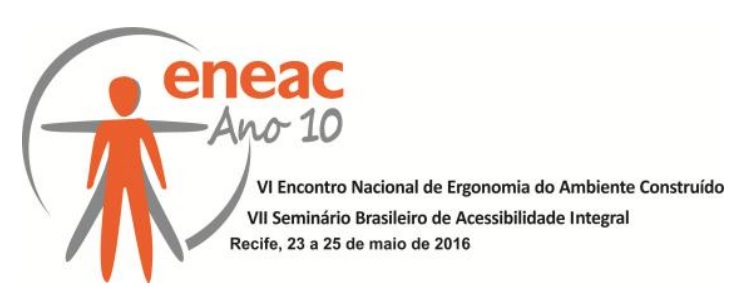

de poder aquisitivo, principalmente as de baixíssimas renda que trata-se de um segmento carente de créditos convencionais para aquisição de moradia digna sem comprometimento do orçamento doméstico.

O programa define padrões técnicos baseados em normas e especificações que devem ser seguidos para a execução das habitações, no entanto estes são de caráter generalistas e não citam questões no que diz respeito à configuração ambiental focada nas particularidades exigidas na interface das mesmas com o seu futuro usuário.

Atentando-se a tal fato esse trabalho relata um estudo desenvolvido tendo como objetivo a análise da maneira como os projetos de habitação social financiados pelo programa Minha casa minha vida estão sendo pensados / projetados enquanto qualidade projetual e capacidade de proporcionar conforto e bem estar ao usuário enfocando aspectos como acessibilidade, desenho universal e conforto ambiental (habitabilidade, acústico, lumínico e térmico). Tal abordagem foi definida, pois entende-se que ao desenvolver-se avaliações ergonômicas do ambiente torna-se possível a geração de dados que apontem possíveis deficiências e/ou qualidades projetuais, que podem ser utilizados como base para correção ou na concepção de novos projetos. É importante destacar ainda que parte-se da premissa que a maneira como o usuário percebe o ambiente que ocupa está diretamente relacionada à maneira como o ambiente apresenta-se configurado, e que, é por meio da interface ambiente / usuário que surgem as sensações de bem estar, conforto e segurança, que podem, ou não, acarretar em qualidade de vida e satisfação.

O desenvolvimento desse trabalho ocorreu em etapas iniciando por uma revisão bibliográfica a respeito do tema, desenvolvimento de metodologia específica, cadastro projetual (identificação, cadastro e visita técnica a conjuntos habitacionais financiados pelo sistema "Minha casa minha vida"), análise ergonômica dos projetos cadastrados e análise dos dados obtidos.

\section{A INTERFACE HABITAÇÃO E O SER HUMANO}

Os relatos mais antigos da civilização humana já apresentavam a busca do homem por adaptar-se ao local que ocupava, imprimindo nesses características pessoais. Tal fato pode ser explicado pelo entendimento de que a interface estabelecida entre o ambiente e o seu ocupante, resultantes das condições que neles são geradas, acarreta em relações que são marcadas por trocas de informações, percepções e reações (Ornestein e Romero (1995) e Löbach (2001)).

A consciência dessa relação acaba por possibilitar, em muitos casos, processos de planejamentos ambientais obtidos pela manipulação de configurações e atrativos de acordo com as intensões de percepção que se pretende que o usuário tenha durante o uso. Em contra mão a tal entendimento tem-se um contexto muito comum que são os edifícios desenvolvidos sem o enfoque no futuro usuário, ou seja, são pensados de maneira generalista desconsiderando as características e necessidades particulares e individuais e variáveis como idade, sexo, dimensões, destreza, força entre outras características. Tal fato, de acordo com Cambiaghi (2007) tem como consequência que somente uma porcentagem reduzida da população utilizará o espaço confortavelmente.

Muitos são os usos que os edifícios podem ter, mas nesse trabalho aborda-se especificamente a habitação e a importância da continua e interminável busca pela qualidade projetual desta, pois como afirma Lopes (2006) o homem moderno passa apenas $25 \%$ do seu tempo no ambiente de trabalho e o resto deste tempo é gasto no ambiente doméstico, meios de transporte e locais públicos. Ou seja, a influência da habitação na qualidade de vida do ser humano é primordial. 


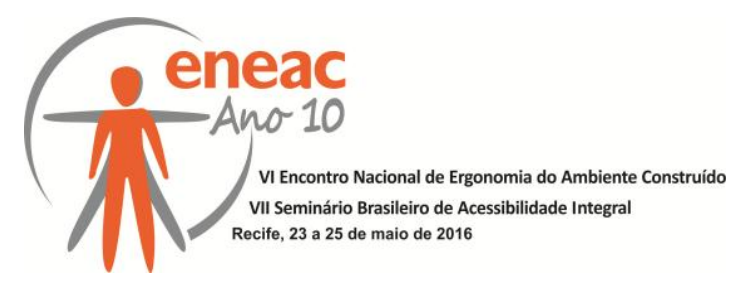

Fazendo-se um recorte na vasta possibilidade dos tipos de habitação e restringindo aos conjuntos habitacionais, identifica-se um forte caráter modular dos projetos com um grande predomínio de uma única planta tipo que é desenvolvida e repetida inúmeras vezes de maneira aleatória e sem qualquer tipo de intervenção que vise melhora ou adequação a aspectos ambientais como orientação solar ou de ventos, ou ainda às particularidades do individuo que a habitará. Cria-se assim um padrão de habitação onde caberá aos futuros moradores adaptarem-se a elas, contexto esse que vem em contramão aos conceitos ergonômicos onde segundo Moraes e Mont'Alvão (2010) o trabalho deve estar adaptado ao trabalhador e o produto ao usuário, de maneira a alcançar a melhor integração possível, ou seja, o local ou objeto deve-se adaptar-se ao homem e não o contrario como relatado. Como consequência Cambiaghi (2007) explicita que o futuro morador, tratado simplesmente como um consumidor que irá adquirir um produto (moradia), para o seu próprio uso ou para a utilização de outras pessoas de seu circulo familiar ou amigos, muitas vezes não faz ideia que passará por dificuldades na utilização dos espaços, que em muitos casos não serão capazes de corresponderem satisfatoriamente às suas necessidades.

Tal contexto evidencia que a concepção de projetos arquitetônicos que melhor atendam as necessidades de moradia com espaços ideais, que proporcionem mais qualidade de vida, deve estar envolto a conceitos e abordagens de diversas áreas de conhecimento. Dessa maneira, a Ergonomia e seu caráter interdisciplinar acaba ocupando papel de destaque, afirmação essa corroborada por lida (2006) ao citar que esta tem contribuído para melhorar a vida cotidiana, não restringindo-se apenas a produtos industriais, mas também a estudos que visam melhorar residências, a circulação de pedestre em locais públicos, meios de transporte mais cômodos e seguros, mobília doméstica mais confortável e os aparelhos eletrodomésticos mais eficientes e seguros ajudar pessoas com deficiências físicas e assim por diante.

Especificamente dentro da ergonomia identifica-se a Avaliação Pós Ocupação (APO) como um segmento para análise de habitação, pois segundo Cambiaghi (2007), essa trata-se de um conjunto de métodos e técnicas para avaliar o desempenho de ambientes construídos, que através dos resultados de suas avaliações pode-se chegar a um diagnóstico e com base nele estabelecer recomendações e intervenções para os ambientes em estudo e diretrizes para futuros projetos. De acordo com Ornstein (1992) a APO pode ser entendida como um método interativo que detecta patologias e determina terapias no decorrer do processo de produção e uso de ambiente construído, através da participação e intenção de todos os agentes envolvidos na tomada de decisões.

No que diz respeito à avaliação do projeto arquitetônico, que vem a ser o objeto de estudo relatado nesse trabalho, a variável que serve de referência é a avaliação funcional, que trata fundamentalmente da avaliação realizada pelos pesquisadores quanto ao desempenho funcional dos espaços: planejamento/ programa do projeto; áreas mínimas; dimensionamentos mínimos; armazenamento; circulação interna (usuários, cargas, equipamentos); fluxos de trabalho; área de lazer e descanso; flexibilização dos espaços; potencialização para mudanças e/ou ampliações; adequação do mobiliário fixo, móveis e equipamentos especiais; sinalização /orientação interna e externa; circulação externa de pedestre e veículos (passeio, caminhões, carga, descarga, estacionamentos); adequação externa e interna a deficientes físicos e visuais (particularmente circulação, sanitários etc.); segurança contra acidentes pessoais; segurança contra roubo; facilidade de manuseio e manutenção de órgãos do edifício, mobiliário e equipamentos (ex: janela, cobertura etc.); relação área útil e área de circulação; e relação efetivamente entre área ocupada e em uso e área eventualmente sem uso (ociosa).

Com base nisso, fica evidente que na concepção do projeto deve-se ter a consciência da extensa diversidade de usuários e suas características mais distintas, de forma a atender 


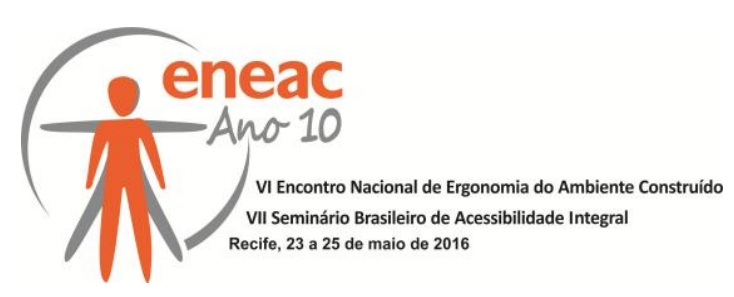

tanto quanto possível em sua plenitude a todos, de maneira confortável e evitando intervenções futuras ou prevendo-as em projeto.

\section{ESTUDO DE CASO}

Esse trabalho relata um estudo desenvolvido tendo por objetivo a análise da maneira como os projetos de habitação social financiados pelo programa Minha casa minha vida estão sendo pensados / projetados enquanto qualidade projetual e capacidade de proporcionar conforto e bem estar ao usuário. Sua primeira parte consistiu em uma revisão bibliográfica a respeito do tema, onde buscou-se embasamento teórico para estruturação de metodologia especifica para o contexto a ser analisado. Em seguida foi definida a metodologia de análise e estruturado um protocolo denominado "Protocolo de avaliação pós-ocupação de habitação social" a ser utilizado como ferramenta de análise, que enfoca aspectos de acessibilidade, desenho universal e conforto ambiental (habitabilidade, acústico, lumínico e térmico). A terceira etapa consistiu na definição dos dois projetos a serem analisados, ambos de habitação social, localizados na cidade de Bauru e com financiamento do programa federal "Minha Casa Minha Vida", faixa II. Por fim foram feitas as análises e considerações.

\subsection{Protocolo de avaliação pós-ocupação de habitação social}

O Protocolo de avaliação pós-ocupação de habitação social foi desenvolvido buscando a configuração de uma ferramenta de análise ergonômica do ambiente construído, sendo sua estrutura composta por três partes: descrição do projeto que fornece dados como nome do conjunto habitacional, localização e dados referentes à empresa responsável pela concepção do projeto e execução da obra, planta, sistema construtivo, programa de necessidades; conforto ambiental enfocando aspectos de habitabilidade, térmicos (relacionando posição de cômodo com orientação solar), lumínicos (relacionando cômodo, metragem quadrada de aberturas enquanto relação de porcentagem de área de piso) e de ventilação (avaliação realizada pela relação entre área quadrada do cômodo comparado à área quadrada ventilada); por fim aborda-se aspectos relativos à medidas antropométricas que comparam as dimensões das aberturas dos cômodos da habitação com os valores exigidos pela norma, assim como as circulações e as áreas de manobras e rotação para cadeirantes existentes.

As analises das condições de habitabilidade devem ser desenvolvidas tendo como referência técnica parâmetros definidos no Código de Obras e Edificações - COE de São Paulo (1992), que considera a relação área construída/habitante, tipo e área dos cômodos. Ao analisar a área quadrada por habitante esse norma estabelece os seguintes índices de avaliação: ótimo quando a metragem do cômodo possuir mais de $25 \%$ acima do mínimo estabelecido, bom - igual ou até $25 \%$ acima do mínimo estabelecido; ruim - até $25 \%$ abaixo do mínimo estabelecido e péssimo - mais de $25 \%$ abaixo do mínimo.

Quando enfoca-se a análise do grau de conforto térmico de cada cômodo deve-se verificarse a implantação da habitação enquanto à posição do sol e verificar se a orientação real condiz com a posição indicada pela norma. Considera-se então como sendo ótimo quando a orientação real da janela corresponde à orientação ideal recomendada; ruim quando a orientação real da janela não corresponde à orientação ideal e péssimo quando o cômodo não tem janela ou quando possui janela interna (ALUCCI, 1998).

Para avaliar a iluminação dos cômodos utilizamos as determinações onde se exige que todos os cômodos devem ter abertura para o exterior, sendo que esta deve possuir uma área mínima de abertura igual ou maior a $1 / 8$ (12,50\%) da área do piso nos casos de 


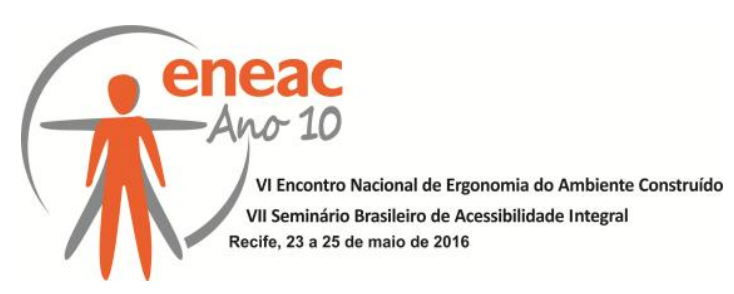

cômodos de permanência prolongada e igual ou maior a $1 / 12(8,33 \%)$ da área do piso não podendo ter área inferior a $0,40 \mathrm{~m}^{2}$ para cômodos de utilização transitória.

A avaliação de conforto térmico ocorrem a partir de critérios que consideram a relação implantação da habitação no terreno e seu posicionamento solar. É importante destacar que quando esse posicionamento da habitação resulta na influência direta em aspectos como redução do consumo de energia elétrica e condições de salubridade como na proliferação de ácaros e fungos. Para o desenvolvimento desta análise foram definidos os seguintes parâmetros:

- Dormitórios: os dormitórios com aberturas para orientação leste propiciam a entrada direta de luz solar no período da manhã e diminuem a probabilidade de proliferação de ácaros e fungos, organismos comuns nesse tipo de ambiente. Considerando categoria $\left(1^{\circ}\right)$ aberturas para orientação Leste e Nordeste, Categoria $\left(2^{\circ}\right)$ aberturas para orientação Norte, Noroeste, categoria ( $\left.3^{\circ}\right)$ aberturas para orientação Oeste e Sudoeste e categoria ( $\left.4^{\circ}\right)$ para aberturas na orientação Sul e Sudoeste;

- Áreas de serviço: áreas de serviço com aberturas para orientação solar de leste/nordeste/norte/noroeste/oeste, propiciam melhor secagem de roupas. Considerando categoria $\left(1^{\circ}\right)$ para aberturas para a orientação leste, noroeste, norte, nordeste e oeste, categoria $\left(2^{\circ}\right)$ para aberturas na orientação sudoeste, categoria $\left(3^{\circ}\right)$ para aberturas na orientação sudeste, categoria (4ํ) aberturas para orientação sul;

- Banheiros e cozinha: banheiros e cozinhas podem, em sua maioria, receber maior incidência solar (norte), pois são cômodos de menor tempo de permanência dos seus usuários. Por estarem sempre úmidos, o sol ajuda na secagem e manutenção do ambiente livre de microrganismos. Considerando categoria $\left(1^{\circ}\right)$ para incidência solar norte, categoria $\left(2^{\circ}\right)$ para incidência solar noroeste e oeste, categoria ( $\left.3^{\circ}\right)$ leste, nordeste, categoria $\left(4^{\circ}\right)$ para incidência solar sul;

- Salas de estar e jantar: sala de estar e jantar, que tem permanência prolongada dos usuários, recomenda-se que estejam voltadas para regiões de menor incidência solar direta (sul). Considerando categoria (1ํ) aberturas para orientação sul e sudeste, categoria $\left(2^{\circ}\right)$ aberturas para orientação leste e nordeste, categoria ( $\left.3^{\circ}\right)$ aberturas oeste e sudoeste e categoria $\left(4^{\circ}\right)$ para aberturas na orientação norte e noroeste.

Por fim aborda-se a ventilação natural que também ocupa importante na promoção de ambientes saudáveis, por ser capaz de dificultar o surgimento de mofos, além de contribuir para a renovação do ar interno. Uma circulação de ar adequada, dentro do ambiente construído, pode reduzir o consumo de energia na edificação, proporcionar ambientes salubres e termicamente confortáveis (CUNHA, 2010). Como critérios de análise estabeleceu-se como sendo um ambiente com boa ventilação interna aqueles que possuem aberturas com metragens correspondentes a $50 \%$ ou mais da área de piso e ruim aqueles que possuem estas com valores inferior a $50 \%$ da área do seu piso.

A última parte do protocolo aborda aspectos relativos à medidas antropométricas e acessibilidade, sendo neste caso utilizados os critérios e parâmetros estabelecidos pela NBR9050, que visa proporcionar à maior quantidade possível de pessoas, independentemente de idade, estatura ou limitação de mobilidade ou percepção, a utilização de maneira autônoma e segura do ambiente, edificações, mobiliário, equipamentos urbanos e elementos. Os itens avaliados são áreas de circulação e manobra para cadeiras de rodas, considerando rotações de $90^{\circ}, 180^{\circ}$ e $360^{\circ}$. 


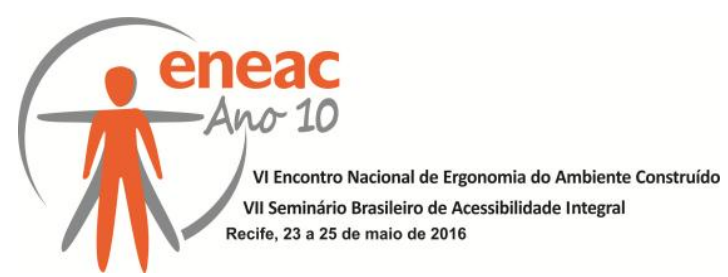

\subsection{Análises}

Foram definidos dois projetos para análise, considerando os pré-requisitos de serem habitação de cunho social construídas com verbas do programa federal Minha casa minha vida. A seguir é apresenta-se os resultados das análises desenvolvidas.

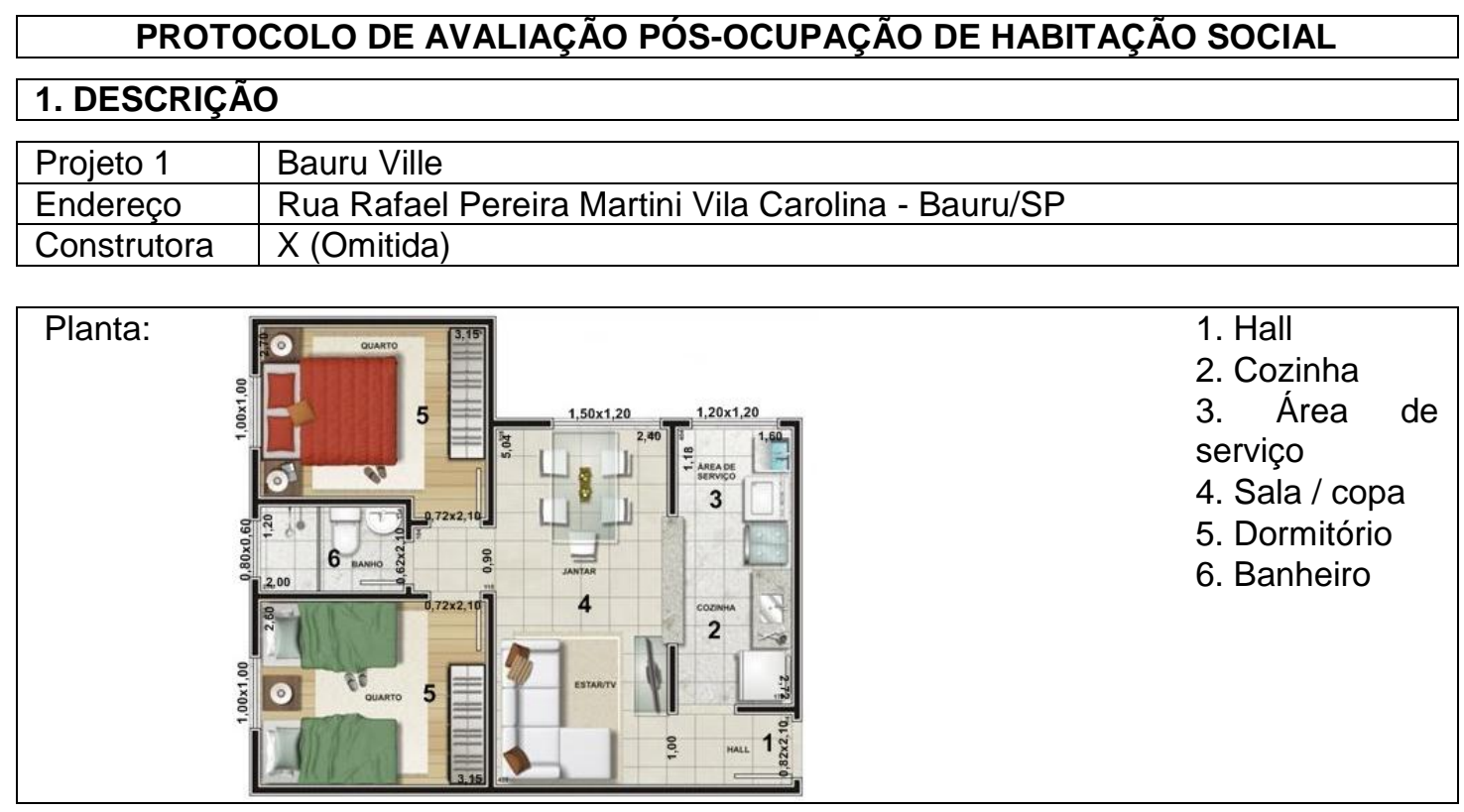

\begin{tabular}{|l|l|}
\hline Sistema Construtivo & $\begin{array}{l}\text { Estrutural em concreto armado pré-moldado e } \\
\text { fechamento em alvenaria de tijolos cerâmicos. }\end{array}$ \\
\hline Programa de Necessidades & $\begin{array}{l}\text { Sala, copa, cozinha, banheiro, dois dormitórios e área } \\
\text { de serviço. }\end{array}$ \\
\hline
\end{tabular}

\section{ANÁLISE DE ESPAÇO HABITÁVEL}

\begin{tabular}{|l|c|c|c|c|c|}
\hline Local & Área $\left(\mathrm{m}^{2}\right)$ & Ótimo & Bom & Ruim & Péssimo \\
\hline Cozinha & $04,35 \mathrm{~m}^{2}$ & & & & $\mathrm{X}$ \\
\hline Sala/copa/dormitório 2 pessoas & $20,28 \mathrm{~m}^{2}$ & & & & $\mathrm{X}$ \\
\hline Sala/copa/dormitório Casal & $19,65 \mathrm{~m}^{2}$ & & & & $\mathrm{X}$ \\
\hline Banheiro & $02,40 \mathrm{~m}^{2}$ & & & $\mathrm{X}$ & \\
\hline Lavanderia & $01,88 \mathrm{~m}^{2}$ & & & $\mathrm{X}$ & \\
\hline
\end{tabular}

\section{CONFORTO AMBIENTAL}

Planta (Indicando o Norte, Avaliação da Insolação)
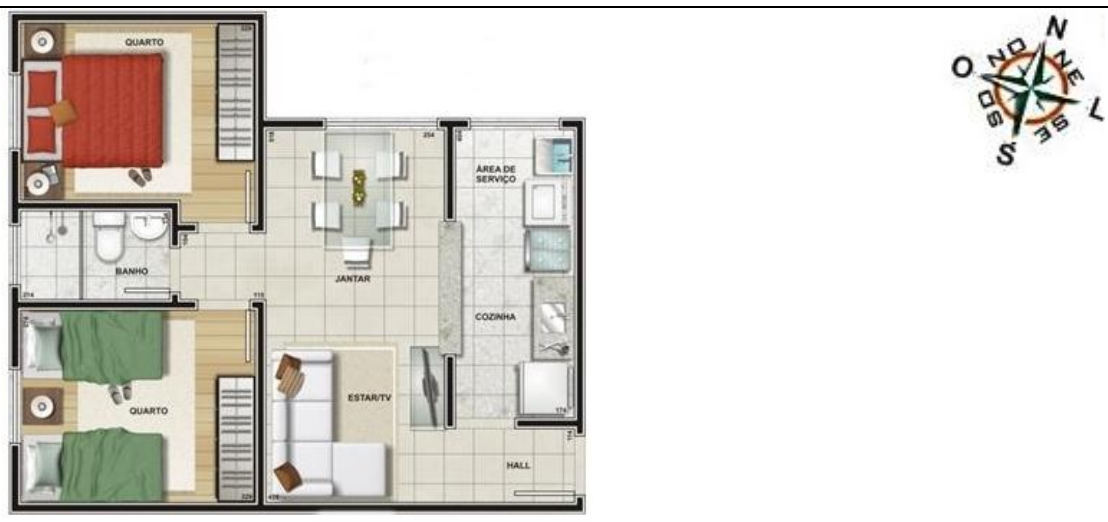

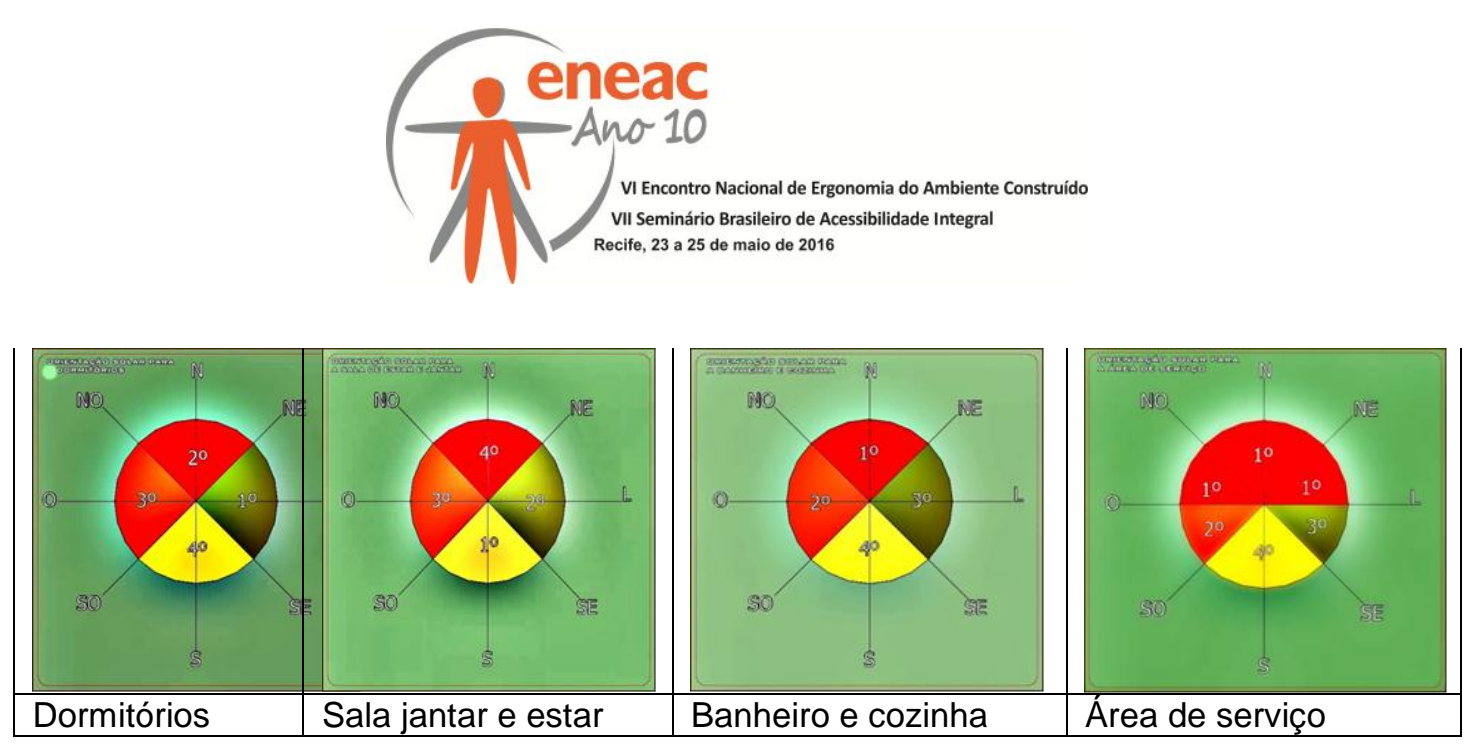

\subsection{AVALIAÇÃO DE CONFORTO TÉRMICO}

\begin{tabular}{|l|l|l|}
\hline Ambiente & Orientação Adequada & Categoria da Incidência do Local \\
\hline Dormitório casal & Leste e Nordeste & $3^{\circ}$ \\
\hline Dormitório solteiro & Leste e Nordeste & $3^{\circ}$ \\
\hline Sala de estar e jantar & Sul e sudeste & $4^{-}$ \\
\hline Cozinha & Norte & $1^{o}$ \\
\hline Banheiro & Norte & $2^{0}$ \\
\hline Área de Serviço & & $1^{-0}$ \\
\hline
\end{tabular}

\subsection{AVALIAÇÃO DO CONFORTO LUMÍNICO}

\begin{tabular}{|l|c|c|c|l|}
\hline Local & Abertura & Área de Piso & Norma & Avaliação \\
\hline Dormitório casal & $1,00 \mathrm{~m}^{2}$ & $07,56 \mathrm{~m}^{2}$ & $12,5 \%$ & OK \\
\hline Dormitório solteiro & $1,00 \mathrm{~m}^{2}$ & $08,19 \mathrm{~m}^{2}$ & $12,5 \%$ & Não Atende \\
\hline Sala/copa & $1,80 \mathrm{~m}^{2}$ & $12,09 \mathrm{~m}^{2}$ & $12,5 \%$ & OK \\
\hline Cozinha/ área de Serviço & $1,44 \mathrm{~m}^{2}$ & $06,24 \mathrm{~m}^{2}$ & $12,5 \%$ & OK \\
\hline Banheiro & $0,48 \mathrm{~m}^{2}$ & $02,40 \mathrm{~m}^{2}$ & $12,5 \%$ & OK \\
\hline
\end{tabular}

\subsection{AVALIAÇÃO DE VENTILAÇÃO}

\begin{tabular}{|c|c|c|c|c|c|}
\hline Local & Área $\mathrm{m}^{2}$ & $\begin{array}{l}\text { Área } \\
\text { ventilada }\end{array}$ & Porcentual & Avaliação & \\
\hline $\begin{array}{l}\text { Dormitório } \\
\text { casal }\end{array}$ & $7,56 \mathrm{~m}^{2}$ & $2,97 \mathrm{~m}^{2}$ & $39,20 \%$ & $<$ a $50 \%$ & \multirow{5}{*}{ 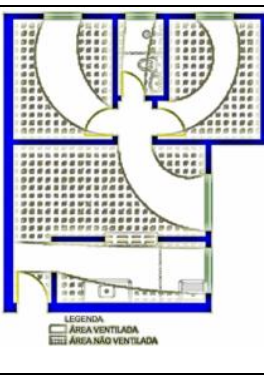 } \\
\hline $\begin{array}{l}\text { Dormitório } \\
\text { solteiro }\end{array}$ & $8,19 \mathrm{~m}^{2}$ & $4,00 \mathrm{~m}^{2}$ & $48,84 \%$ & $<$ a $50 \%$ & \\
\hline Sala/copa & $12,09 \mathrm{~m}^{2}$ & $3,30 \mathrm{~m}^{2}$ & $27,29 \%$ & $<$ a $50 \%$ & \\
\hline $\begin{array}{l}\text { Cozinha/ } \\
\text { área de } \\
\text { serviço }\end{array}$ & $6,24 \mathrm{~m}^{2}$ & $4,73 \mathrm{~m}^{2}$ & $75,80 \%$ & $>$ a $50 \%$ & \\
\hline Banheiro & $2,40 \mathrm{~m}^{2}$ & $1,48 \mathrm{~m}^{2}$ & $61,66 \%$ & $>$ a $50 \%$ & \\
\hline
\end{tabular}

\section{Medidas Antropométricas}

\begin{tabular}{|l|l|l|l|}
\hline Acessibilidade (planta) $90^{\circ}, 180^{\circ}, 360^{\circ}$ \\
\hline
\end{tabular}




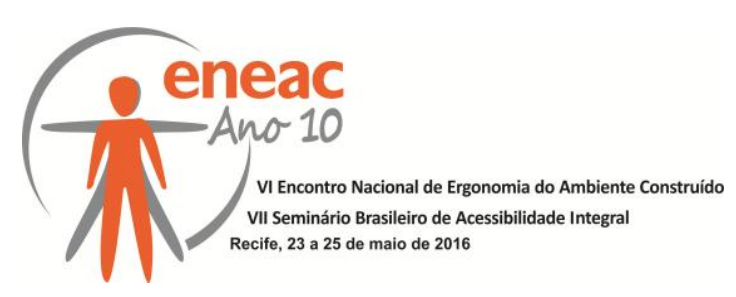

\subsection{Avaliação antropométrica de acessibilidade}

\begin{tabular}{|l|l|l|l|}
\hline $\begin{array}{l}\text { Aberturas } \\
\text { (dimensões) }\end{array}$ & Norma & Local & Análise (NBR 9050) \\
\hline Porta banheiro & $0,80 \times 2,10$ & $0,62 \times 2,10$ & Não atende \\
\hline Porta entrada & $0,80 \times 2,10$ & $0,82 \times 2,10$ & Atende \\
\hline Porta Dorm. casal & $0,80 \times 2,10$ & $0,72 \times 2,10$ & Não atende \\
\hline Porta Dorm. Solteiro & $0,80 \times 2,10$ & $0,72 \times 2,10$ & Não atende \\
\hline Escadas & $\begin{array}{l}2 \mathrm{e}+\mathrm{b}=63 \text { ou } 64 \mathrm{~cm}( \\
\text { Blondell) }\end{array}$ & Não possui & - \\
\hline Rampa & $8,33 \%$ de incl. & Não possui & - \\
\hline Elevadores & NBR 13994 & Não possui & - \\
\hline
\end{tabular}

Os resultados das análises mostraram que o projetos possui deficiência, citando-se primeiramente o não atendimento da NBR 9050, pois as medidas de circulação e das aberturas das portas impedem a realização de manobras e passagem de cadeiras de rodas. Outro fato é que o tamanho dos cômodos não atingem as medidas mínimas por habitante, definidas por norma. E por fim, considera-se que as questões de conforto ambiental (térmico e lumínico), apresentam-se prejudicadas pela incorreta implantação do apartamento e consequente posicionamento de suas aberturas relativa à orientação solar. Pode-se concluir, portanto, que há necessidade e um redimensionamento espacial e de um reposicionamento das aberturas. Cabe destacar ainda que os itens avaliados influenciam diretamente na qualidade de vida e saúde os usuários da habitação.

\section{CONSIDERAÇÕES}

Diante do déficit habitacional brasileiro, o governo em busca de mudança de tal contexto, criou o sistema de financiamento habitacional "Minha casa minha vida" direcionando-o principalmente à população de baixa renda. Entretanto, ao observar-se a analise desenvolvida torna-se clara a ausência de preocupações mínimas com aspectos que dizem respeito à qualidade ambiental e acessibilidade.

Com o levantamento bibliográfico e o estudo de caso apresentado foi possível coletar dados importantes que poderão auxiliar no entendimento das deficiências ou qualidades projetual, que futuramente podem ser utilizados como base para correção ou na concepção de novos projetos.

Os resultados das análises mostraram que os dois projetos possuem deficiências, citandose primeiramente o não atendimento da NBR 9050, pois as medidas de circulação e das aberturas das portas impedem a realização de manobras e passagem de cadeiras de rodas. Outro fato é que o tamanho dos cômodos não atingem as medidas mínimas por habitante, definidas por norma.

E por fim, cita-se que as questões de conforto ambiental (térmico e lumínico), apresentamse prejudicadas pela incorreta implantação dos apartamentos relativa à orientação solar e as aberturas. Pode-se concluir, portanto, que há necessidade e um redimensionamento espacial e do posicionamento das aberturas. Cabe destacar ainda que os itens avaliados influenciam diretamente na qualidade de vida e saúde os usuários da habitação. 


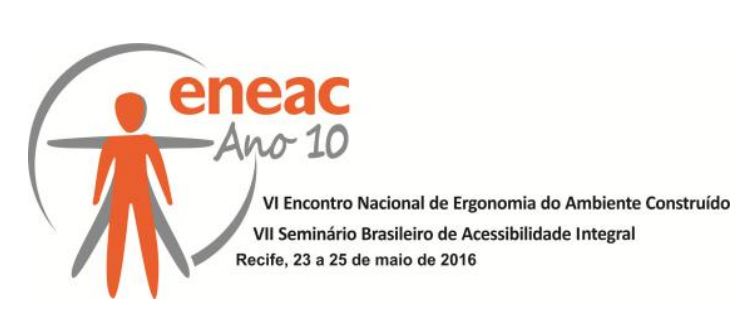

\section{REFERÊNCIAS BIBLIOGRÁFICAS}

ASSOCIAÇÃO Brasileira de Normas Técnicas ABNT NBR 9050- Acessibilidade a Edificações, mobiliário, espaços e equipamentos urbanos, 2007.

ALUCCI, Márcia et al. Implantação de Conjunto Habitacionais. Recomendações para Adequação Climática e Acústica. São Paulo: IPT, 1996.

CAMBIAGHI, Silvana. Desenho Ambiental: Metodos e Técnicas para arquitetos. São Paulo: Editora Senac, 2007.

Código de Obras de Edificações - COE de São Paulo, Lei n¹1.228/92.

CUNHA, L. J. B. D. F. Análise de métodos para aplicação de ventilação natural para projeto de edificações em Natal-RN. 2010. p. (Dissertação de Mestrado) - Programa de Pós-Graduação em Arquitetura e Urbanismo, Universidade Federal do Rio Grande do Norte, Natal, 2010.

IIDA, Itiro. Ergonomia: projeto e produção. $2^{\circ}$ Edição ver. e ampl. São Paulo: Ed. Edgard Blücher, 2005.

LÖBACH, Bernd. Design Industrial - bases para a configuração dos produtos industriais. Traduzido por: Freddy Van Camp. São Paulo: Ed. Edgard Blücher LTDA. 2001. Tradução de: Industrial Design - Grundlangen der Industrieproduktgestaltung

LOPES, Maria Valéria Affonso. Ergonomia aplicada à habitação: o caso do usuário enfermo. Dissertação (Mestrado - Área de Concentração: Tecnologia da Arquitetura) - FAUUSP. 2006.

MORAES, Anamaria de; MONT'ALVÃO, Claudia. Ergonomia: conceitos e aplicações. Rio de Janeiro: Ed. 2AB, 2000. 2ํㅡㄹ Edção

ORSNTEIN, S; BRUNA, G.; ROMÉRO, M. Ambiente construído e comportamento: a avaliação pós-ocupação e a qualidade ambiental. São Paulo: Ed. Nobel - FAUUSP, 1995.

ORSNTEIN, Sheila. Avaliação Pós-Ocupação do Ambiente Construído. São Paulo: Ed. Nobel 1992. 